\title{
Retroflexion and Retraction Revised ${ }^{*}$
}

\author{
Silke Hamann, OTS Utrecht
}

\begin{abstract}
Arguing against Bhat's (1974) claim that retroflexion cannot be correlated with retraction, the present article illustrates that retroflexes are always retracted, though retraction is not claimed to be a sufficient criterion for retroflexion. The cooccurrence of retraction with retroflexion is shown to make two further implications; first, that non-velarized retroflexes do not exist, and second, that secondary palatalization of retroflexes is phonetically impossible. The process of palatalization is shown to trigger a change in the primary place of articulation to non-retroflex. Phonologically, retraction has to be represented by the feature specification [+back] for all retroflex segments.
\end{abstract}

\section{Introduction}

Retroflex consonants are usually described as sounds articulated with a bent-backwards tongue tip and a postalveolar place of articulation, e.g. by Catford (1977: 150) or Trask (1996: 308). As illustrated in Hamann (in prep.), a number of retroflex segments deviate from this definition. The retroflex stops and nasals in Hindi, for example, do not show a bending backwards of the tongue tip but these sounds are still considered to be phonetically and phonologically retroflex. The same holds for the voiced and voiceless postalveolar fricatives in Polish and Russian (ibid.), which are articulated without active involvement of the tongue tip in the constriction (though the tip is raised from its resting position) and with a flat tongue body.

The class of retroflexes shows considerable articulatory variation regarding both the articulator (i.e. apical or subapical to laminal), and the place of articulation (i.e. alveolar to palatal). This variation makes it difficult to find common articulatory properties that hold for all instances of retroflexion.

In his article 'Retroflexion and Retraction', Bhat (1974) discusses the property of retraction as a defining criterion for retroflexion. He states that most retroflexes are retracted, and this retraction can explain both the occurrence of retroflexes with back vowels and their incompatability with front vowels. Retroflex segments and back vowels are both assigned the feature value [+back], and front vowels the feature value [-back]. Nevertheless, Bhat argues that retraction is not a criterion that holds for all retroflexes and furthermore not for retroflexes exclusively. As an example of languages with non-retracted retroflex segments, he mentions the vowel system of the Dravidian language Badaga and the consonantal system of Tamil. As evidence for the non-exclusiveness of retraction to retroflexes, Bhat mentions that apical alveolars ${ }^{1}$ are also retracted.

The present study agrees with Bhat's second statement that retraction holds not exclusively for retroflexes but that all apicals (and velars) are retracted. In contrast to Bhat it

\footnotetext{
The ideas for this article emerged from two talks on the complementary nature of palatalization and retroflexion held at at the $33^{\text {rd }}$ Poznań Linguistic Meeting, Poznań, and the Uil-OTS Utrecht, in April and May 2001, respectively. I want to thank the audience for their input. Furthermore I am grateful to T.A. Hall for comments on an earlier version of this study. All errors are my own.

1 'Apical alveolars' is used here in general for all apical coronals which are [+anterior], including apical dentals.
} 
is claimed here that all retroflexes are retracted. This claim is formalized in the implication in (1), which says that if a segment is retroflex, then it is retracted (but not vice versa).

\section{(1) retroflex $\rightarrow$ retracted}

From the implication in (1) it follows that there are no non-retracted retroflexes, and consequently so-called non-retroflex segments in Tamil and Badaga are claimed to be phonetically non-retroflex. The inherent retraction of retroflexes further implies that retroflexes cannot be palatalized, because the articulatory gestures of retraction and palatalization are incompatible. It will be argued that secondarily palatalized retroflexes either undergo a change in primary place of articulation (and in segment class) or resist palatalization altogether.

The study proceeds as follows. In section 2, the term 'retraction' is articulatorily defined and its correlation with retroflexion is illustrated. Section 3 is concerned with supposedly non-retracted retroflexes in Lardil and Badaga. In section 4, the claim that palatalization and retraction are incompatible is elaborated and apparent counterexamples (Kashmiri and Tamil) are discussed. Section 5 discusses the consequences of retroflexes being retracted for a phonological representation. The final section concludes.

\section{$2 \quad$ Definition of 'retraction'}

Bhat (1974) defines retraction as the backing of the tongue body. This backing can be further specified by the place in the vocal tract where the tongue retracts to, namely towards the pharynx or the velum. The former is often referred to as pharyngealization and the latter as velarization. Thus, the term retraction seems to subsume two secondary articulations. The term pharyngealization is usually used to refer to a secondary vowel articulation (e.g. by Ladefoged \& Maddieson 1996: 365) where the root of the tongue is drawn back and towards the back wall of the pharynx. Velarization is understood as a secondary articulation where the tongue back is raised towards the velum (e.g. by Laver 1994 or Trask 1996: 374). In some phonetic literature, the term 'velarization' is actually used in the more general sense of retraction. Brosnahan \& Malmberg (1970: 67), e.g., define velarization as 'the elevation of the back of the tongue toward the soft palate or rear wall of the pharynx', which actually covers both velarization and pharyngealization as defined above.

Ladefoged (1971: 208) points out that there is little articulatory difference between velarized and pharyngealized sounds and no language distinguishes between these two. Language-specific evidence for the interchangeable use of pharyngealization and velarization comes from Russian. Russian speech sounds are traditionally described as opposing palatalized and velarized consonants. Bolla (1981), however, describes the latter as 'pharyngealized' because he 'found the movement of the root of the tongue and the postdorsum towards the pharyngeal wall to be more important than that towards the soft palate' (p. 70).

'Retraction' is defined in the present article as a displacement of the tongue dorsum or root towards the pharynx or velum. A schema of these possible displacements is given in 0 , based on x-ray tracings of velarized and pharyngealized segments in Laver (1994: 326ff.) and Ladefoged \& Maddieson (1996: 365). 


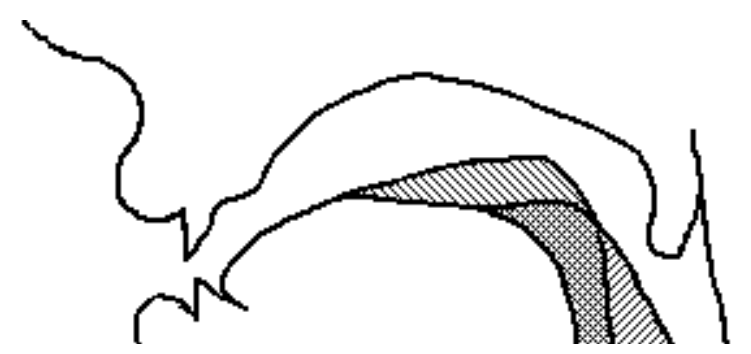

Figure 1: Retraction, indicated as shaded areas, in comparison to neutral tongue position. The upper displacement is a velarization gesture, the lower pharyngealization.

The legitimacy of combining the distinct secondary articulations pharyngealization and velarization as one property is further confirmed by the fact that they are described as resulting in the same acoustic consequence, namely a lowering effect on the third formant (Brosnahan \& Malmberg 1970; Stevens 1998). Both velarization and pharyngealization occur with a flattening of the tongue body, which is included here as a characteristic of 'retraction'.

The property 'retraction' is not identical to the feature 'retracted tongue root' (opposed to 'advanced tongue root', see Halle \& Stevens 1969), because this articulatory setting involves a pharyngeal constriction at a lower place in the vocal tract than for pharyngealization (Laver 1994: 411). Furthermore, retraction as defined here is different from McCawley's (1966) feature 'retracted articulation' by which he distinguishes dentals from alveolars and retroflexes from palatals (amongst others), the second item in each pair being [+retracted] (and thus ascribing retroflex a non-retracted status).

The co-occurrence of retroflexion with retraction as predicted in (1) can be explained articulatorily. The tongue, in order to be able to move its tip upwards, stretches and pulls the muscles backwards (Spencer 1984: 30), which results in a backed and flattened or even hollowed tongue dorsum. Further evidence for the correlation of a flat tongue body with retraction and retroflexion can be found in Ladefoged (1971: 208) who explains that the similarity in quality between retroflex stops and velarized or pharyngealized stops "is due to the fact that in all these sounds the front of the tongue is somewhat hollowed" (ibid).

The flattening of the tongue body and its retraction in retroflex segments are also mentioned in Brosnahan \& Malmberg (1970: 46) who explain that retroflexion is accomplished by the concaving of the dorsum and blade, i.e. by a flattening of the tongue dorsum. Catford (1977: 157) illustrates that retroflex fricatives have a tongue body that is less convex than in lamino-postalveolar articulations and that they show some velarization. Language-specific descriptions showing a correlation between retroflexion and retraction include Polish and Bulgarian. Hamilton (1980: 21), for example, uses the terms velarization and retroflexion interchangeably for the postalveolar fricative in Polish, and Wood (1996) writes that the Bulgarian retroflexed / $r$ / involves a pharyngeal tongue body gesture.

Bhat (1974) argues that retraction is not restricted to retroflexes but that it also occurs with apical alveolars. Stevens et al. (1986: 436) argue against this view and claim that a fronted tongue body provides a more favorable posture for an apico-alveolar articulation, i.e. that a non-retroflex apical usually occurs with fronted, non-backed tongue body. This is illustrated with schematic midsagittal sections (ibid. figure 20.4). Below these schemas, the authors say that the tongue-body shape behind to the tongue blade has been only estimated, i.e. no X-ray or other data are given to confirm their claim. X-ray tracings of apicals (such as found in Ladefoged \& Maddieson 1996 or Butcher 1992) illustrate that apicals generally show a retracted tongue dorsum.

Retraction of the tongue body (towards the velum) seems to occur distinctively in the articulation of velar consonants (see e.g. x-ray tracing of velar stops and fricatives in Laver 
1994). Thus retraction cannot be assumed to occur exclusively with retroflexes. But whereas Bhat discussed retraction as the only defining criterion for retroflexion and refutes this criterion with the argument that it does not distinguish retroflexes from apicals, the present study argues that retraction is only one of several properties of retroflexion. Additional phonetic properties for retroflexes such as apicality, posteriority and sublingual cavity are developed in Hamann (in prep.). Independent of the status of these defining properties, retraction is a necessary property of retroflexe, i.e. it cannot be lacking in a retroflex. In conclusion, retroflex segments are always retracted.

\section{$3 \quad$ Non-retracted retroflexes? The cases of Badaga and Lardil}

Using retraction as a defining property of retroflexion poses problems with languages that are said to have a distinctively non-retracted (i.e. non-velarized or non-pharyngealized) retroflex segment.

According to Bhat (1974: 234), the Dravidian language Badaga contrasts plain, retroflex, and retracted vowels. Badaga is the only known language to employ such a contrast. Using retraction and retroflexion contrastively implies that these two properties do not cooccur together in the retroflex segments of this language. Bhat bases his description of Badaga vowels on Emeneau (1939), who describes the three-way contrast however as one of "nonretroflexed, half-retroflexed, and fully-retroflexed vowels'. Examples for this are given in (2), with Emeneau's transcription.

$\begin{array}{lll}\text { Plain vowel } & \text { half retroflexed } & \text { fully retroflexed } \\ \text { kae 'unripe fruit' } & \text { áé 'tiger's den' } & \text { käe 'weeds' }\end{array}$

Bhat justifies his re-classification of Emeneau's 'half-retroflexed' vowels as 'retracted' by the fact that they are described as having the edges of the tongue tip curved upwards only, but not the whole tongue, and that they show strong retraction (p. 234). As no definition of retroflexed vowels is given which says that these segments have to include a curving of the whole tongue tip backwards, Bhat's classification is not motivated. We assume therefore Emeneau's classification to be correct, which poses no counterevidence for the assumption that the characteristic 'retraction' holds for retroflex vowels, too.

A far more serious counterexample to the claim that retroflexion always co-occurs with retraction seems to be the Australian Aboriginal language Lardil. Lardil is supposed to have phonetically and phonologically non-velarized retroflex consonants (Wilkinson 1988; Hall 1997, 2000). The phonetic evidence for this claim comes from Hall (1997: 49) who gives midsagittal tongue tracings of non-velarized and velarized retroflexes from the languages Lardil and Polish, respectively. The source for the figure of the non-velarized retroflexes in Lardil is said to be Stevens et al. (1986). Stevens et al., however, do not provide any graphic illustrations of the Lardil coronal. The only figure that might have served as basis for Hall's graphic is a schematized retroflex stop in figure 20.4 on page 433, based on Ladefoged \& Bhaskararao (1983) and Wierzchowska (1971). These authors describe retroflexes in Hindi, Tamil and Polish. The schematic figure of a retroflex based on their work shows a distinct backing of the tongue body and is explicitly described as 'more backed' than an apical dental or a laminal postalveolar in the following text. In their phonetic description of Lardil sounds at a later point, Stevens et al. (p. 444f.) observe that [+distributed, -anterior] segments, i.e. laminal postalveolars, are [-back] in this language. Hall (1997) presumably misapplied this correlation to [-distributed, -anterior], i.e. retroflex, segments and concluded that Lardil is a language with [-back], i.e. non-velarized, retroflexes. 
Phonological evidence for the non-retracted status of the Lardil retroflexes is given in Wilkinson (1988) and Hall (1997, based on the former). Lardil allows only a subset of coronals in coda-position, namely all apart from the lamino-dental $[\mathrm{t}, \mathrm{n}]$ and the postalveolar glide [j]. The whole coronal inventory of Lardil is given in table 1 (based on Wilkinson 1988). ${ }^{2}$

Table 1: Coronals in Lardil, boldface ones allowed in Coda position

\begin{tabular}{|l|c|c|c|c|}
\hline & $\begin{array}{c}\text { lamino- } \\
\text { dental }\end{array}$ & $\begin{array}{c}\text { apico- } \\
\text { alveolar }\end{array}$ & $\begin{array}{c}\text { lamino- } \\
\text { postalveolar }\end{array}$ & $\begin{array}{c}\text { apico-domal } \\
\text { (retroflex) }\end{array}$ \\
\hline obstruents & $\mathbf{t}$ & $\mathbf{t}$ & $\underline{\mathbf{t}}$ & $\mathbf{t}$ \\
\hline nasals & $\mathbf{n}$ & $\mathbf{n}$ & $\underline{\mathbf{n}}$ & $\mathbf{n}$ \\
\hline lateral & & $\mathbf{l}$ & & $\mathbf{l}$ \\
\hline glides & & & $\mathbf{j}$ & $\mathbf{r}$ \\
\hline flap & & $\mathbf{f}$ & & \\
\hline
\end{tabular}

To account for the class of [t, $\left.n_{n}, j\right]$ which cannot occur in coda position, Wilkinson makes use of the feature [back] and assigns the value [+back] only to the lamino-dentals. This yields a feature specification of Lardil coronals as given in table 2.

Table 2: Feature specification of Lardil coronals with [back] according to Wilkinson (1988: 327)

\begin{tabular}{|c|c|c|c|c|}
\hline & $\begin{array}{c}\text { lamino- } \\
\text { dental }\end{array}$ & $\begin{array}{c}\text { apico- } \\
\text { alveolar }\end{array}$ & $\begin{array}{c}\text { lamino- } \\
\text { postalveolar }\end{array}$ & $\begin{array}{c}\text { apico-domal } \\
\text { (retroflex) }\end{array}$ \\
\hline [back] & + & - & - & - \\
\hline
\end{tabular}

In this classification, the lamino-dentals $[\mathrm{t}, \mathrm{n}]$ are united under one feature, and thus the phonotactic restriction in Lardil can be described as forbidding [+back] segments in codaposition. This proposal makes it necessary to specify the retroflex segments of Lardil as [-back], which has to be phonetically interpreted as non-retracted. Wilkinson bases this feature specification on Stevens et al. (1986)3, but these authors illustrate that retroflexes have a more backed tongue body than laminal postalveolars (recall discussion above), i.e. they do not confirm Wilkinson's assumption about the non-retraction of Lardil retroflexes. As a further point of criticism it has to be added that Wilkinson's class of [+back] segments does not include the postalveolar glide [j].

As justification for the use of the feature [back], Wilkinson (1986: 328) discusses a process whereby the apical alveolar / $\mathrm{t} /$ becomes a laminal postalveolar [t] before the back vowel $[u]$. The only example given for this is the underlying /yarput/ 'snake, bird', which becomes [yarputur] in the future and [yarputar] in the marked nonfuture.4 This example is not convincing for two reasons. First, no evidence for the underlying form being an alveolar is given. And second, the spread of the feature [+back] onto the alveolar can be caused by a following back vowel $[\mathrm{u}]$ only in the case of the future form, where the morpheme [ur] is added. The marked nonfuture morpheme [ar] does not contain a back vowel and thus no

\footnotetext{
${ }^{2}$ The use of the IPA symbols is my own. The term 'laminal postalveolar' is based on Evans' (1995: 727f.) description of Lardil, which is phonetically more detailed than Wilkinson, who describes this class as 'laminal alveolar'. Wilkinson furthermore does not include the retroflex lateral in her inventory.

${ }^{3}$ Wilkinson refers to "Kawasaki, Keyser, and Stevens (1986)" as the source, but the reference list shows that this is meant to be Stevens et al. (1986).

${ }^{4}$ As Wilkinson (1988: 325) explains, nouns in object position agree in tense with the verb.
} 
feature [+back] that could trigger a change, but still this form surfaces with a laminal postalveolar.

An alternative solution to unite the Lardil coronals that do not occur in coda-position is by referring to the features [distributed] and [anterior]. A classification by these features is given in table 3 .

Table 3: Feature specification of Lardil coronals with [anterior] and [disributed]

\begin{tabular}{|l|c|c|c|c|}
\hline & $\begin{array}{c}\text { lamino- } \\
\text { dental }\end{array}$ & $\begin{array}{c}\text { apico- } \\
\text { alveolar }\end{array}$ & $\begin{array}{c}\text { lamino- } \\
\text { postalveolar }\end{array}$ & $\begin{array}{c}\text { apico-domal } \\
\text { (retroflex) }\end{array}$ \\
\hline [anterior] & + & + & - & - \\
\hline [distributed] & + & - & + & - \\
\hline
\end{tabular}

Now, the class of $[\mathrm{t}, \mathrm{n}, \mathrm{j}]$ can be described as [+anterior, +distributed] stops and nasals, and [+distributed] glides.

In sum, it is phonologically not necessary and phonetically not motivated to describe the class of Lardil retroflexes as [-back]. As no other counterexample with a non-retracted retroflex is known to me, no language with a non-retracted retroflex seems to exist, which affirms the implication made before that retraction always co-occurs with retroflexion.

\section{$4 \quad$ Retraction and palatalization}

Besides implying that non-velarized or non-pharyngealized retroflexes do not occur, the retroflex property 'retraction' introduced here has a further implication. If retroflex segments are inherently retracted, they should not be compatible with secondary palatalization, because a simultaneous articulation of palatalization and velarization or pharyngealization is articulatory incompatible. An explanation for this incompatability comes from articulation. The palatalization of consonants involves a raising of the tongue dorsum and a lowering of the tongue back, whereas retraction has the opposite articulatory consequences of flattening the tongue dorsum and raising the back. Both gestures cannot co-occur together.

Evidence for the claim that palatalized retroflexes are non-existent is found in Maddieson's (1984) typological study, which lists no language with a phonemic palatalized retroflex segment. Only two counterexamples could be found in the phonetic and phonological literature, namely Toda (Emeneau 1984; Spajić et al. 1996) and Kashmiri (Bhat 1987), which are both said to have palatalized retroflexes. It is argued in this section that these segments are not retroflex, and that the process of palatalization triggers a change in the retroflex segment from apical to laminal (as proposed already in Hall 2000) and from flat tongue dorsum to bunched tongue dorsum. The second change implies the loss of retraction, thus the resulting segment is ssumed to be non-retroflex.

This section proceeds as follows. In 4.1, traditional definitions of palatalization as mere additional articulations are shown to be inadequate for coronal sounds. Then, to illustrate the change from retroflex to non-retroflex occurring with palatalization, the Russian retroflex fricative and its palatalized counterpart are discussed. In 4.2, the alleged palatalized retroflex segments in Toda and Kashmiri are treated and the status of these segments is analyzed. Alternative descriptions for these supposedly palatalized retroflexes are proposed and it will be concluded that there are no counterexamples for the claim that secondary palatalization of retroflexion does not occur. 


\subsection{Palatalization as a change in primary articulation}

Palatalization in traditional articulatory terms is defined as the superimposition of an [i]-like gesture upon a labial, dental, alveolar or postalveolar consonant (e.g. Ladefoged \& Maddieson 1996). This superimposition of a gesture is undoubtedly the case for labials with a secondary palatalization, where the tongue dorsum gesture can take place independently and at the same time as the labial closing gesture. But for primary gestures with the tongue tip, blade or dorsum, the primary and secondary gestures are not independent of each other and therefore are expected to influence each other, which results in a change of the primary place of articulation. Support for this asssumed change can be found in Ladefoged (1971: 207) who points out that "the terms palatalization and palatalized may also be used in a slightly different way from a secondary articulation, namely as describing a process in which the primary articulation is changed so that it becomes more palatal." Ladefoged \& Maddieson (1996: 365) further specify this by stating that for all coronal consonants, secondary palatalization always involves a displacement of the surface of the tongue. This displacement is said to produce a slightly different primary constriction location (ibid.). It is concluded from this, that the traditional description of a secondary palatalization is inaccurate in the case of coronal segments, as this process always involves a change in the primary articulation for coronal sounds.

Articulatory evidence for a change of place in palatalized apical dentals is given in Scatton (1975) for Bulgarian and Čavar \& Hamann (2002) for Polish. Hall (2000) argues that apical stops in general either turn into laminal stops when palatalized (in a synchronic or diachronic process), or resist palatalization altogether.

For retroflex segments, it is proposed here that the addition of a palatalization gesture also involves a change in primary articulation. This change results in a non-retroflex segment. Support for this proposal can be found in Ladefoged (1971: 208), who mentions that the secondary articulations of palatalization, velarization and pharyngealization involve different shapes of the tongue that cannot occur simultaneously. As velarization and pharyngealization were defined as realizations of the retroflex criterion 'retraction' in section 1, Ladefoged's remark can be interpreted as an articulatory incompatibility of retroflexion and palatalization.

The incompatibility of gestures and the change in primary place is exemplified with the Russian fricatives in the postalveolar region. Figure 2 is based on x-ray tracings of the Russian retroflex fricative (solid line) and its palatalized counterpart (dashed line) (both based on Bolla 1981: 159). As illustrated in Hamann (2002), the Russian postalveolar fricative is a retroflex which satisfies the property of retraction. ${ }^{5}$

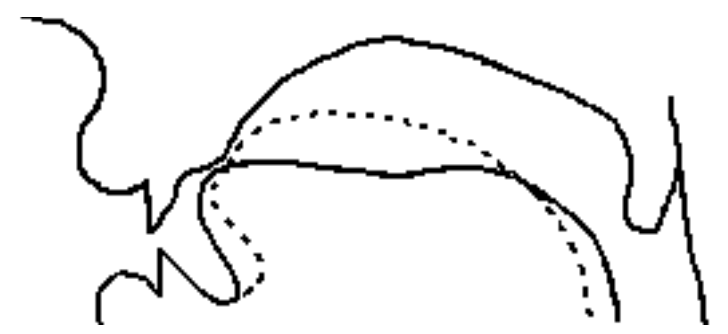

Figure 2: Russian retroflex fricative (solid line) and palatalized postalveolar fricative (dashed line)

Comparing now the palatalized variant with the retroflex one, some major differences can be observed. First of all, the place of articulation changes for the palatalized segment; it moves

\footnotetext{
5 Hamann (2002) argues that the Russian voiced and voiceless postalveolar fricatives satisfy three of the four properties for retroflexion introduced there, namely apicality, sublingual cavity and retraction, and is therefore retroflex.
} 
further backwards to the postalveolar region, which gives evidence for the assumed change in primary articulation for retroflex segments. Furthermore, the articulator is now the tongue blade, and the tongue dorsum shape changes to bunched and raised. The resulting segment has a domed tongue, hence no retraction is discernible. This leads to the conclusion that the resulting segment is not retroflex, as it does not fulfill the necessary property of retraction.

As palatalization in general involves the addition of or change towards an [i]-like gesture, and [i] and other front, high vowels are always articulated with a bunched tongue dorsum, this implies that secondary palatalization of retroflexion always results in a change in the property retraction. But as apicality is assumed to always co-occur with retraction, a further change from apical to non-apical is necessary. The process of secondary palatalization of a retroflex segment is therefore assumed to result in a laminal postalveolar. For the fricative [s] this results in the palato-alveolar fricative [ $\left.\int^{\mathrm{j}}\right]$, cf. (3a). The secondary palatalization of a retroflex stop and nasal is assumed to trigger likewize changes, see ( $3 \mathrm{~b})$ and $(3 \mathrm{c})$, respectively.

$$
\begin{array}{ll}
\text { (a) } & {\left[\mathrm{s}^{\mathrm{j}}\right]=\left[\mathrm{j}^{\mathrm{j}}\right]} \\
\text { (b) } & {\left[\mathrm{t}^{\mathrm{j}}\right]=[\mathrm{t}] \text { or }[\mathrm{c}]} \\
\text { (c) } & {\left[\mathrm{n}^{\mathrm{j}}\right]=[\mathrm{n}] \text { or }[\mathrm{n}]}
\end{array}
$$

Hume (1994) assumes that the palatalized postalveolar in Polish is a palatalized retroflex $\left[\mathrm{s}^{\mathrm{j}}\right]$. At the same time, she specifies this sound as [coronal, -anterior, +distributed, +strident]. The specification as [+distributed] indicates that this sound is laminal, i.e. articulated with a long constriction, and not retroflex. Therefore Hume's description implies that the process of palatalization in Polish actually changes a retroflex fricative into a laminal postalveolar, as stated in (3).

Besides the categorical change described above, another possible outcome of secondary palatalization of retroflexes is to resist palatalization at all, as pointed out by Hall (2000). He gives an example from Scots Gaelic, where nouns usually undergo palatalization in the genitive singular, e.g. [ $\left[\mathrm{k}^{\mathrm{h}} \mathrm{at}{ }^{\mathrm{h}}\right]$ 'cat' (nom.sg.) surfaces as $\left[\mathrm{k}^{\mathrm{h}} \mathrm{at} \mathrm{t}^{\mathrm{hj}}\right]$ 'cat' (gen.sg.). Nouns with retroflex consonants, however, remain unpalatalized, e.g. [pa:t] 'a poet' (both nom. and gen. sg.) (Borgstrøm 1940: 76). A resistance to palatalization is otherwise only reported for apical alveolars or dentals (e.g. Hall 2000), which were described as also being inherently retracted in section 1 . The property retraction can be made responsible for blocking palatalization, for the same articulatory reason that causes this property to change into nonretraction in secondary palatalized retroflexes, namely articulatory incompatability. As all apicals are retracted, this explains why apicals in general change category when palatalized or resist palatalization altogether.

In sum, it was shown that retraction is incompatible with palatalization, which results in two possible outputs for retroflex palatalization, either a corresponding palatalized laminal, or a plain retroflex without palatalization.

\subsection{Apparent counterexamples: Toda and Kashmiri}

According to Emeneau (1984), and Spajić et al. (1996), the Dravidian language Toda employs palatalized versions of all its three rhotics, including the retroflex trill $/ \mathrm{r}$. Minimal pairs such as [or] 'to cook' vs. [or ] 'foot', or [tor] 'thigh' vs. [tor $\left.{ }^{j}\right]$ 'pole used at funeral' illustrate the alleged contrast between plain and palatalized retroflex rhotic. Interestingly, Spajić et al. (1996) could elicit retroflex rhotics and their palatalized counterparts only from some of their subjects; the three speakers of the Kas mund (tribal location). The three speakers of the 
Melgas mund did not produce any of these forms. ${ }^{6}$ Though presenting a detailed phonetic study of these rhotics, Spajić et al. (1996) do not include any palatographic or linguographic measurements of the palatalized trill $/ \mathrm{f}^{\mathrm{j}} /$, from which the exact articulation and the correlation of the gesture of retroflexion and that of palatalization can be judged. In order to attest the claim made here that the two gestures do not occur simultaneously, articulatory measurements on the Toda palatalized rhotics have to be conducted in the future.

Palatalized retroflex segments are said to also occur in the Indo-Aryan language Kashmiri (Bhat 1987: 43ff.). Kashmiri has the phonemes $/ t^{\mathrm{j}}, \mathrm{t}^{\mathrm{hj}}, \mathrm{d}^{\mathrm{j}} /$. Wali \& Koul (1997: 297) illustrate these phonemes with the minimal pairs given in (4).

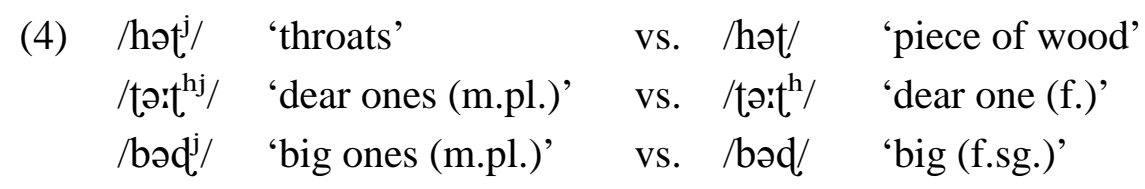

Maddieson's (1984) phoneme inventory of Kashmiri (based on Kelkar \& Trisal 1964) does not include palatalized retroflex phonemes; the only retroflexes given there are the plain plosives $/ \mathrm{t}, \mathrm{t}^{\mathrm{h}}, \mathrm{d} /$. Morgenstierne (1941) also does not mention palatalized retroflexes in Kashmiri. The cause for this discrepancy in the description of the Kashmiri phoneme inventory are probably the so-called mātrā vowels. Mātrā vowels are extremely short (Maddieson 1984: 271 terms them 'overshort') or 'whispered' vowels (Masica 1991: 121), which cause changes in the quality of the preceding vowels and consonants. The -i-mātrā is said to leave a palatalizing effect on the preceding consonant. The assumption of such a short /i/ vowel makes the postulation of separate palatalized consonants redundant. Thus, in some descriptions of Kashmiri, e.g. Grierson (1911) and Morgenstierne (1941), the use of a retroflex segment with a following -i-mātrā stands for what is described as palatalized retroflex by others, e.g. Bhat (1987) and Wali \& Koul (1997). Bailey (1937) even uses a retroflex plus a full-length vowel /i/ in his transcriptions of these segments in Kashmiri. In (5), a comparison of the different transcriptions is given with the masculine singular agentive form of the adjective 'big'.

$\begin{array}{ll}\text { Wali \& Koul (1997) } & \text { Grierson (1911) } \\ \text { b3d }^{\mathrm{j}} & \text { bad }^{\mathrm{i}}\end{array}$

Bailey (1937)

bзdi

Contradictory statements can be found in the literature on the question whether these 'palatalized retroflexes' in Kashmiri should be treated as phonetically and phonologically one segment or as a sequence of a retroflex with a short vowel or glide. Bhat (1987) remarks that the presence of "very short vowels" in contemporary Kashmiri has become obsolete, indicating that there is no reason (neither phonetically nor phonologically) to assume a sequence of two gestures or two phonemes. In his description of Kashmiri, Morgenstierne (1941) however points out that there are differences in the phonetic realization within the group of mātrā vowels. Whereas -u and - $\ddot{\mathrm{u}}$-mātrā (both causing velarization of the preceding consonant) are said to be inaudible by now in Morgenstierne (1941: 87), -i-mātrā still sounds like a very short [i], indicating a separate, additional i-gesture. As in the case of Toda, no articulatory data could be found for Kashmiri illustrating the actual realization of palatalized retroflexes, which could answer the question whether a simultaneous combination of retroflexion and palatalization gesture takes place.

The present study assumes that a combination of retroflexion and palatalization at the same time is impossible, and that the alleged patalalized retroflex segments in Toda and

\footnotetext{
${ }^{6}$ Spajić et al. (1996) do not mention what these speakers produce instead; it can be only speculated that these were non-palatalized retroflex rhotics.
} 
Kashmiri have to be accounted for in another way. I propose that these segments are actually not retroflexes with a superimposed palatalized gesture, but phonetically sequences of a retroflexed segment followed by a short glide $/ \mathrm{j} /$. This proposal does not imply that the palatalized segment, which consists of two successive gestures, has to be phonologically interpreted as two phonemes instead of one. Toda and Kashmiri seem to be languages that chose to interpret the two gestures as belonging to one phoneme.

An indication that these gestures are indeed separate can be seen in the diachronic development of the assumedly palatalized retroflexes in Kashmiri. Diachronically, the mātrā vowels in Kashmiri stem from normal length vowels which have been shortened wordfinally (Morgenstierne 1941: 89). Kashmiri hence had two separate gestures which were assigned to different phonemes, a consonantal and a vocalic one. These gestures were categorized at a later stage as belonging to one phoneme.

Further evidence for the claim that there are two gestures instead of one can be found in the acoustic signal of the Toda trills (Spajić et al. 1996: 19). The signal for the palatalized trill $/ \mathrm{f}^{\mathrm{j}}$ / is $190 \mathrm{~ms}$ long, compared to the non-palatalized $/ \mathrm{r} /$ which is $100 \mathrm{~ms}$. The palatalized counterpart is thus nearly twice as long. There is no articulatory explanation why a palatalized segment should take longer to articulate than a non-palatalized one if one assumes that the two gestures co-occur together. If assuming however that two gestures are produced successively, the nearly double length of the palatalized segment compared to the nonpalatalized is explainable.

In order to judge the values for palatalized and non-palatalized segment lengths, let us compare them to length measurements (in ms) of the palatalized and non-palatalized segment pairs in Russian from Bolla (1981), cf. the tables in (6) and (7), giving the labial articulations and the tongue dependent articulations, respectively. The labial articulations are discussed first, as they involve an independent secondary tongue gesture of palatalization.

\begin{tabular}{|l|c|c|c|c|c|l|}
\hline \multirow{2}{*}{} & \multicolumn{6}{|c|}{ Labial } \\
\cline { 2 - 7 } & $\mathrm{p}$ & $\mathrm{b}$ & $\mathrm{f}$ & $\mathrm{v}$ & $\mathrm{m}$ & ratio \\
\hline plain & 116 & 120 & 128 & 115 & 97 & 1 \\
\hline palatalized & 170 & 140 & 130 & 125 & 97 & 1.14 \\
\hline
\end{tabular}

For this class, the length ratio of plain vs. palatalized is $1: 1.14$. This means that the palatal segment is on average a seventh longer than the plain segment. Thus, the secondary gesture seems to need some additional time to be articulated. It is striking that the values of all labial pairs lie rather close together apart from the voiceless stops, where [p] is $116 \mathrm{~ms}$ and $\left[\mathrm{p}^{\mathrm{j}}\right]$ is $170 \mathrm{~ms}$ long. Why this pair is departing so much from all the other labials cannot be answered here.

Velar and coronal articulations are expected to show roughly the same length for plain and secondary palatalized segments, because the palatalization is not an added gesture but changes the primary articulation (recall the description in 4.1). These expectations are fulfilled by the velar class (cf. left side of table (7)), where the palatalized signals are just slightly longer than the plain ones, as the ratio of 1: 1.08 indicates. The coronal class, however, departs from this picture; it has a ratio of $1: 1.17$, which is higher than that for the labial class. As both velar and coronal sounds undergo a change in primary articulation when palatalized, these results are unexpected. But looking at the coronal segments in detail we detect that this class does not behave homogenously. Whereas for the plosives and the voiced fricative the palatalized segment is longer than the plain one (the ratio varies there between 1 : 1.17 for the voiced plosive and 1: 1.66 for the voiced fricative), for the nasal and the voiceless 
fricative the plain signal is longer (average of $1: 0.91$ ). Again, no explanation for this behavior can be given.

(7)

\begin{tabular}{|l|l|l|l|l|l|l|l|l|l|l|}
\hline & \multicolumn{4}{|c|}{ Velar } & \multicolumn{7}{c|}{ Coronal } \\
\cline { 2 - 12 } & $\mathrm{k}$ & $\mathrm{g}$ & $\mathrm{x}$ & ratio & $\mathrm{t}$ & $\mathrm{d}$ & $\mathrm{n}$ & $\mathrm{s}$ & $\mathrm{z}$ & ratio \\
\hline Plain & 169 & 150 & 110 & 1 & 134 & 102 & 105 & 195 & 96 & 1 \\
\hline palatalized & 184 & 160 & 120 & 1.08 & 190 & 120 & 98 & 177 & 160 & 1.17 \\
\hline
\end{tabular}

The Tamil retroflex rhotics have a ratio of $1: 1.9$ for plain vs. palatalized signal length, which is by far higher than any of the Russian ratios. This difference supports the claim made before that there might be two successive gestures involved in the articulation of the palatalized retroflex in Tamil, whereas palatalization of non-retroflex segments in Russian either is a simultaneous articulation of two gestures (as in the case for labials), or involves only one primary gesture, which differs from the non-palatalized counterpart (as in the case for coronals and velars).

Unfortunately, we do not have any further measurements for palatalized rhotics, so the present data are merely an indication that the hypothesis of successive instead of simultaneous gestures could hold. Further research has to be conducted on the exact articulation and gestural timing of palatalized rhotics in general and palatalized retroflex in particular. This may shed light on the articulatory timing of the gestures and further properties of their articulation.

\section{Phonological representation}

There is consensus in the phonological literature that retroflex segments are to be presented with the feature specification [coronal, -anterior, -distributed] (e.g. Chomsky \& Halle 1968; Hume 1994; Hall 1997). The frequent co-occurrence of retroflexes with back vowels and their tendency to avoid front vowel context, as described e.g. by Bhat (1974) or Flemming (2001), lead several scholars such as Lin (1989) and Gnanadesikan (1994) to propose the addition of the dorsal feature-value [+back] in the representation of retroflexes. [+back] is phonetically defined as retraction. A complete representation of retroflexes with these features is given in (8).

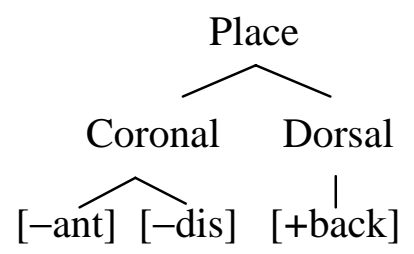

Hall (1997, 2000), who assumes that Lardil has plain, i.e. non-velarized and non-palatalized, retroflex segments, proposes a presentation of retroflexes that can account for such segments and that differs slightly from that in (8). He introduces a three-way contrast of velarized, palatalized, and neither velarized nor palatalized retroflexes such as $\left[\mathrm{t}^{\mathrm{\gamma}}\right]$, $\left[\mathrm{t}^{\mathrm{j}}\right]$, and $[\mathrm{t}]$, respectively. All three classes share the place features [coronal, -anterior, -distributed]. They differ in the values that they are assigned for the dorsal feature [back]. Velarization is expressed by [+back], palatalization by [-back], and a plain retroflexion by [0back], for the last case the tongue back is assumed to be in neutral or unspecified position. This distinction is unnecessary if one assumes that all retroflexes are velarized, as it was argued for in the previous sections. Instead, the universal representation of all retroflex segments with the 
feature value [+back] is a phonological realisation of the phonetic implication made in (1), that all retroflexes are retracted.

The change of a retroflex segment into a laminal postalveolar in the process of secondary palatalization has to be phonologically represented as following. Laminal postalveolars are uncontroversally [coronal, -anterior, +distributed]. Furthermore, the domed, palatalized tongue dorsum of these segments has to be represented with a dorsal feature [-back]. The change of a retroflex to a laminal postalveolar in palatalizing front vowel context can then be accounted for by the feature [-back] spreading from the front vowel onto the retroflex (see e.g. Lin 1989 on the assumption that front vowels are [-back]). As a segment with the specification [coronal, -anterior, -distributed, -back] is phonetically not interpretable since [-distributed], i.e. apicals, have to be [+back], the palatalization process triggers a further change from [-distributed] to [+distributed]. The resulting segment, which is specified as [coronal, -anterior, +distributed, -back], has to be phonetically interpreted as a laminal postalveolar.

\section{Conclusion}

The present article took as starting point Bhat's (1974) study on the possible correlation of retroflexion and retraction. In his article, Bhat concluded "it is clear that retroflexion cannot be identified or correlated with retraction" (p. 237). It has been shown that the first of Bhat's observations, that retroflexion is not identical to retraction, is valid, as all apicals (and also velars) are retracted and thus retraction cannot be used as single defining property for retroflex segments. This problem can be solved by introducing further phonetic properties (as developed in Hamann in prep.) to define retroflexion. But opposing Bhat, it was illustrated that retroflexion always correlates with retraction, and that retroflex vowels in Badaga and retroflex consonants in Lardil are no counterexamples to this claim, since they are neither phonetically nor phonologically non-retracted.

From the correlation of retroflexion with retraction follows that retroflexes cannot be palatalized, because the gestures of retroflexion and palatalization are articulatory incompatible. It has been shown that there are alternative explanations for supposedly palatalized retroflexes in languages such as Toda and Kashmiri, but further research has to be conducted on these segments in order to support or disprove the hypothesis of successive retroflexion and palatalization gestures. 


\section{References}

Bailey, T.G. (1937) The pronunciation of Kashmiri. London: RAS.

Bhat, D.N.S. (1974) "Retroflexion and Retraction.” Journal of Phonetics 2: 233-237.

Bhat, R. (1987) A descriptive study of Kashmiri. Delhi: Amar Prakashan.

Bolla, K. (1981) A Conspectus of Russian Speech Sounds. Budapest: Hungarian Academy of Science.

Brosnahan, L.F. \& Bertil Malmberg (1970) Introduction to Phonetics. Cambridge: Heffer \& Sons.

Borgstrøm, C.H. (1940) A linguistic survey of the Gaelic dialects of Scotland, vol. I: The dialects of the outer Hebrids. Norsk Tidsskrift for Sprogvidenskap. Suppl. Bind I. Oslo: Aschehoug.

Butcher, Andrew (1992) "The phonetics of neutralisation: the case of Australian coronals.” In: Jack Windson (ed.) Studies in general and English phonetics. London: Routledge; 10-38.

Catford, John C. (1977) Fundamental Problems in Phonetics.Edinburgh: University Press.

Ćavar, M. \& S. Hamann (2002) "Polish velar and coronal palatalization - its perceptual background." Ms. to be published in Proceedings of the Fourth European Conference on Formal Description of Slavic Languages.

Chomsky, Noam and Morris Halle (1968) The Sound Pattern of English. New York: Harper and Row.

Emeneau, M.B. (1939) “The vowels of the Badaga language.” Language 15 (1); 43-47.

Evans, Nick (1995) "Current Issues in the Phonology of Australian Languages.” In: John Goldsmith (ed.) The Handbook of Phonological Theory. London: Blackwell; 723-740.

Flemming, Edward (2001) Auditory Representations in Phonology. Routledge: London.

Gnanadesikan, Amalia (1994) "The Geometry of Coronal Articulations." NELS 24,1: 125-139.

Grierson, George (1911) Standard manual of the Kashmiri language. 2 vols. Jammu: Light and Life.

Hall, T. Alan (1997) The Phonology of Coronals. Amsterdam: John Benjamins.

Hall, T.A. (2000) “Typological generalizations concerning secondary palatalization.” Lingua 110: 1-25.

Halle, Morris \& Kenneth Stevens (1969) 'On the feature "advanced tongue root." Quarterly Progress Report 94. Cambridge, MA: Research Laboratory of Electronics, MIT, 209-215.

Hamann, Silke (in prep.) Phonetics and Phonology of Retroflexes. Ph.d. thesis manuscript of the University of Utrecht.

Hamilton, William S. 1980. Introduction to Russian Phonology and Word Structure. Columbus: Slavica.

Hume, Elizabeth (1994) Front Vowels, Coronal Consonants and their Interaction in Nonlinear Phonology. London: Garland.

Kelkar, A. R. \& P. N. Trisal (1964) 'Kashmiri word phonology: a first sketch.' Anthropological Linguistics 6,1: 1322.

Ladefoged, Peter (1971) Preliminaries to Linguistic Phonetics. Chicago: UCP.

Ladefoged, Peter \& Peri Bhaskararao (1983) "Non-quantal Aspects of Consonant Production: A Study of Retroflex Consonants." Journal of Phonetics 11: 291-302

Ladefoged, Peter \& Ian Maddieson (1996) The Sounds of the World's Languages. Oxford: Blackwell.

Laver, John (1994) Principles of Phonetics. Cambridge: CUP.

Lin, Yen-Hwei (1989) “The Retroflex as a Complex Segment.” ESCOL 6: 182-193.

Maddieson, Ian (1984) Patterns of Sounds. Cambridge: CUP.

Masica, Colin (1991) The Indo-Aryan languages. Cambridge: Cambridge University Press.

McCawley, James (1966) "Further revisions in Finnish rules." Unpublished paper, University of Chicago.

Morgenstierne, Georg (1941) "The Phonology of Kashmiri.” Acta Orientalia 19,1: 79-99.

Scatton, Ernest A. (1975) Bulgarian Phonology. Columbus: Slavica Publishers.

Spajić, Siniša, Peter Ladefoged \& P. Bhaskararao (1996) “The trills of Toda." Journal of the International Phonetic Association 26,1: 1-21.

Spencer, Andrew (1984) "Eliminating the feature [lateral]." Journal of Linguistics 20: 23-43.

Stevens, Kenneth, Samuel Keyser and Haruko Kawasaki (1986) "Toward a phonetic and phonological theory of redundant features.” In: J.S. Perkell and D.H. Klatt (eds.) Invariance and Variability in Speech Processes. Hillsdale: Erlbaum. 426-449.

Stevens, Kenneth (1998) Acoustic Phonetics. Cambridge, Massachusetts: MIT Press.

Trask, R.L. (1996) A Dictionary of Phonetics and Phonology. London: Routledge.

Wali, Kashi \& Omkar N. Koul (1997) Kashmiri: A cognitive-descriptive grammar. London: Routledge.

Wierzchowska, Bożena (1971) Wymowa Polska. Warzawa: Państwowe Zakłady Wydawnictw Szkolnych.

Wilkinson, Karina (1988) 'Prosodic Structure and Lardil Phonology.' Linguistic Inquiry 19,2: 325-334.

Wood, Sidney A.J. (1996) "Assimilation or coarticulation? Evidence from the temporal co-ordination of tongue gestures for the palatalization of Bulgarian alveolar stops.” Journal of Phonetics 24: 139-164. 